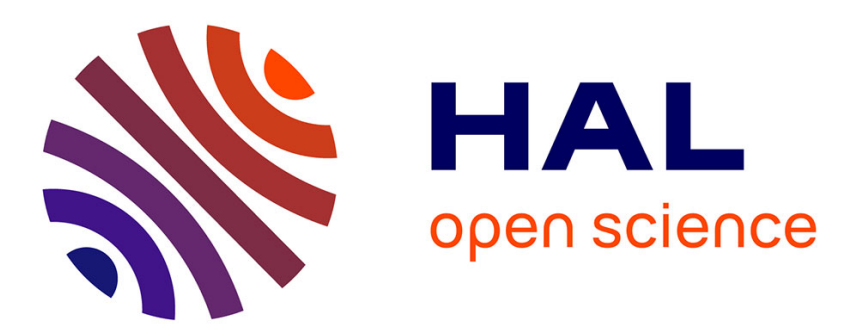

\title{
Characterization of the mechanical properties of thermal barrier coatings by 3 points bending tests and modified small punch tests
}

Pierre Planques, Vanessa Vidal, Philippe Lours, Vincent Proton, Fabrice Crabos, Julitte Huez, Bernard Viguier

\section{To cite this version:}

Pierre Planques, Vanessa Vidal, Philippe Lours, Vincent Proton, Fabrice Crabos, et al.. Characterization of the mechanical properties of thermal barrier coatings by 3 points bending tests and modified small punch tests. Surface and Coatings Technology, 2017, 332, p.40-46. 10.1016/j.surfcoat.2017.09.070 . hal-01656551

\section{HAL Id: hal-01656551 \\ https://hal.science/hal-01656551}

Submitted on 4 Dec 2019

HAL is a multi-disciplinary open access archive for the deposit and dissemination of scientific research documents, whether they are published or not. The documents may come from teaching and research institutions in France or abroad, or from public or private research centers.
L'archive ouverte pluridisciplinaire HAL, est destinée au dépôt et à la diffusion de documents scientifiques de niveau recherche, publiés ou non, émanant des établissements d'enseignement et de recherche français ou étrangers, des laboratoires publics ou privés. 


\title{
Characterization of the mechanical properties of thermal barrier coatings by 3 points bending tests and modified small punch tests
}

\author{
Pierre Planques $^{\mathrm{a}, \mathrm{b}, \mathrm{c}, *}$, Vanessa Vidal ${ }^{\mathrm{b}}$, Philippe Lours ${ }^{\mathrm{b}}$, Vincent Proton ${ }^{\mathrm{c}}$, Fabrice Crabos $^{\mathrm{c}}$, \\ Julitte Huez ${ }^{a}$, Bernard Viguier ${ }^{a}$ \\ a CIRIMAT, Université de Toulouse, UPS-INP-CNRS, INP/ENSIACET, 4 allée Emile Monso, BP 44362, 31030 Toulouse cedex 04, France \\ b Université de Toulouse, CNRS, Mines Albi, INSA, UPS, ISAE, ICA (Institut Clément Ader), Campus Jarlard, F-81013 Albi, France \\ ' Safran Helicopter Engines, Avenue Joseph Szydlowski, 64511 Bordes, France
}

\section{A B S T R A C T}

The Atmospheric Plasma Sprayed Thermal Barrier Coatings (APS TBCs) is commonly used to insulate hot sections in gas turbines. Cyclic oxidation failure usually results from the spallation of the ceramic top coat. In order to predict such spalling phenomena, understanding the mechanisms for cracks initiation and propagation in thermal barriers is a major issue for engine-makers. Failure of the TBC is strongly related to the thermal and mechanical properties of each component of the multi-materials system (substrate, bond coat and ceramic) but also to the response of the TBC as a whole. The purpose of the present work is to assess the mechanical behavior of a complete TBC using comparative experimental (uniaxial and biaxial loading) and Digital Images Correlation (DIC) analysis approaches for classical TBC microstructures obtained through APS coatings.

The experimental characterization of the mechanical behavior of the TBC systems was studied on as deposited specimens. Three Points Bending (3PB) tests were performed at room temperature, with the ceramic coating either under tension or compression. Additionally, in situ observations during 3PB tests by a camera, associated to a DIC analysis, allow determining the evolution of the strain field of surface sample correlated with the damage evolution. Location of crack initiation and crack propagation paths up to macroscopic failure were investigated. These tests highlighted the strong differences in mechanical behavior and fracture mode depending on the tension or compression stress state in ceramic coating. Small Punch Tests (SPT) were also performed at room temperature using both geometries (tension/compression). This allows pointing out the similarities of failure modes between uniaxial solicitation and biaxial flexure. Tests performed at $850{ }^{\circ} \mathrm{C}$ in the SPT ring show that when temperature varies, different mechanical properties can be observed.

Keywords:

Plasma spray

Thermal barrier coatings

Mechanical properties

Failure mode

\section{Introduction}

In hot sections of gas turbine engines, the thermal insulation systems deposited on static parts as combustion chambers or outer air seals (segments or rings) in aircraft engines and on blades and vanes in landbased engines, are composed by APS TBCs. The standard APS TBC system consists in a bilayer system composed by a $150 \mu \mathrm{m}$ thick MCrAlY ( $\mathrm{M}=\mathrm{Ni}$ and/or Co) bond coat and a $250-1000 \mu \mathrm{m}$ thick $\mathrm{ZrO}_{2}$ stabilized with 7-8 wt $\% \mathrm{Y}_{2} \mathrm{O}_{3}$ (YSZ) ceramic top coat. In the present study, we focus on thick APS TBC applying on static parts of helicopter engines.

Under normal operation conditions TBC experiences rather complex loading combined with the existence of residual stresses and oxidation processes. Therefore, it is difficult to predict the dominant driving force which causes the failure. Additionally, the microstructure of the constituents, namely $\mathrm{TBC}$, bond coat (BC) and the substrate, continuously changes and modifies the mechanical response. Upon cumulative thermo-mechanical cycles imposed to the engine, APS TBCs are known to mainly fail by spallation of the ceramic top coat. Then, in order to build and properly implement a relevant model of life duration for a use of design purpose by engine-makers, it is of first order to understand such spalling phenomena and to predict the life duration of the thermal barrier coatings. That is the reason why we propose a mechanical characterization of YSZ samples with standard microstructure classically obtained for APS coatings (lamellar, porous and micro-cracked).

The literature [1-4] reports the trend that each TBC system seems to show its own set of properties (Young's Modulus, tensile strength, fracture toughness, ...) depending on its specific microstructure

\footnotetext{
* Corresponding author at: CIRIMAT, 4 allée Emile Monso, BP 44362, 31030 Toulouse cedex 04, France.

E-mail addresses: pierre.planques@ensiacet.fr (P. Planques), vanessa.vidal@mines-albi.fr (V. Vidal), philippe.lours@mines-albi.fr (P. Lours), 
characteristics (density, porosity, thickness, ...). Despite the large scattering of bibliographical results, even for a given and fixed fabrication procedure, obtaining reliable mechanical properties of YSZ proves to be complex and a real issue.

Concerning the failure modes, it has clearly been shown that the adherence of the top coat is one of the most important parameter for the durability of TBC systems [5-7]. Different testing techniques with the goal of studying the influence of mechanical strains on damage evolution and failure has been reported in the literature. Conventional standard uniaxial 3-(or 4-) Points Bending (3PB) tests are often employed to evaluate the delamination resistance and to investigate the interfacial properties of brittle materials such as TBC [8-11]. But they show limitations: i) they are inappropriate for strength measurements as edge defects enable to initiate early failure and ii) they are not representative of the real load of components which is rather biaxial than uniaxial. Therefore biaxial bending tests on disc-shaped specimens are often preferred for many applications, especially in ceramic and nuclear industries [12-15]. As they require easy and straightforward specimen preparation and drastically limit the contribution of edge defects to failure. However, to the authors' knowledge, this technique has never been used to study the delamination resistance or the interfacial properties of TBC systems.

In this study, the mechanical behavior of thick complete TBC samples is obtained through 3PB and Small Punch Tests (SPT). Simple bending tests offer ideal conditions to study crack initiation and damage evolution under purely mechanical loading. Problematic in all the investigations is the precise detection of a critical strain value at which the TBC starts to undergo a process of damage localization and formation of macroscopic cracks. Indeed, long before the appearance of visible cracks, the TBC undergoes a phase of macroscopically homogenous quasi-plastic deformation, occurring mainly due to the growth of micro-cracks and frictional gliding. We present below results of 3PB tests performed with the TBC subjected to both tensile and compressive in-plane stresses. Simultaneous optical inspection of the interface area was used as in situ diagnostics. This allowed investigating, using the Digital Image Correlation (DIC) method, the correlation between continuously increasing strain and the process of macroscopic crack formation and propagation. The comparison of loading behavior and cracking process between $3 \mathrm{~PB}$ and SPT is then presented at room temperature. The SPT is finally performed at $850{ }^{\circ} \mathrm{C}$. All these results are discussed regarding the literature knowledge.

\section{Material and methods}

APS $\mathrm{ZrO}_{2}-8 \mathrm{wt} \% \mathrm{Y}_{2} \mathrm{O}_{3}$ thermal barrier coatings were used for the mechanical investigation. The different samples are obtained by spraying the deposit on sand blasted Ni-based substrates in plate or disc shaped samples. The plate samples used for 3PB were made of Hastelloy $\mathrm{X}$ and had a length of $50 \mathrm{~mm}$, a width of $25 \mathrm{~mm}$ and an average thickness of $1.3 \mathrm{~mm}$. The SPT specimens were IN738 superalloy discs with a thickness of $2 \mathrm{~mm}$ and a diameter of $20 \mathrm{~mm}$. On both types of substrates, the $200 \mu \mathrm{m}$ bond-coat was obtained through APS deposition of NiCrAlY powder. The top coat of 8YSZ was air plasma sprayed to obtain a $1.1 \mathrm{~mm}$-thick deposit (with approximately $12 \%$ porosity). The $\mathrm{TBC} / \mathrm{BC}$ interface roughness was in the order of $\mathrm{Ra}=11-12 \mu \mathrm{m}$ (technical measure).

After spraying, specimens for 3PB tests were machined in the shape of parallelepipeds with dimensions $25 \times 5 \times 2.6 \mathrm{~mm} 3$. All the specimens were tested in as-sprayed state, which means neither oxidation nor aging treatment was applied.

The tests were performed on a universal testing facility (INSTRON type 1362) with a load cell of $500 \mathrm{~N}$ or $5 \mathrm{kN}$ (depending on the load level needed). The 3PB device is composed by a punch and support rods made by a $5 \mathrm{~mm}$ radius steel cylinder, and the distance between the two supports is $20 \mathrm{~mm}$. As compared to four point bending, 3PB tests lead to inhomogeneous strain distribution over the sample length with a local maximum at the central loading position. This has advantage for camera observation as the position of first crack occurrence is most likely known in advance. A camera with a macro lens using a magnification factor of 2 was used to record images along the deformation process. Pictures were taken every $2 \mathrm{~s}$ over an observation area of 10 over $10 \mathrm{~mm}$. The minimum displacement measure under these conditions equals about 3 to $5 \mu \mathrm{m}$. The displacement rate of the punch was $0.1 \mathrm{~mm} / \mathrm{min}$. Those images were used for measuring the gross deflection of the TBC but also to compute the local deformation field across the thickness of the whole system using DIC.

DIC analysis has been realized using the commercial software ARAMIS. DIC is a 2D or 3D optical method used for automatically measuring the differences between two images. It is increasingly used in materials science to determine deformation fields, detect cracks or provide displacement fields for identifying material properties. In order to be able to track the surface points of the sample during the test, the surface was previously textured using grinding paper at the grade 360 . A grazing light of the sample associated with the relief gave enough texture on the specimen surface to apply satisfactorily the DIC technique.

DIC is a technique for measuring the displacement field of a surface on a distorted image with respect to a reference image. It is therefore assumed that any difference between the reference image and the deformed image arises from the sole effect of the displacement field of the observed structure. The global method consists in tracking subsets of pixels at the different steps along deformation test to rebuild the strain field of the sample. The method of correlating so-called "local" images is the most widely used today, and is based on the use of the crosscorrelation function. The cross-correlation function is an operator that acts on two functions ( $f(x, y), g(x, y)$ ), each corresponding to an image. This operator is equal to 1 when the two functions are identical and to tend towards -1 when the functions are different. In $2 \mathrm{D}$, to measure the relative displacement of two images along the $\mathrm{x}$ and $\mathrm{y}$ axes, a correlation algorithm using this operator, takes as functions $\mathrm{f}$ and $\mathrm{g}$ respectively portions of the reference and deformed images. The algorithm searches for the values of displacements $\mathrm{dx}$ and dy such that $\mathrm{g}(\mathrm{x}$ $+d x, y+d y)$ maximizes the correlation operator with $\mathrm{f}$. These values are retained as the best estimations of the displacements of the image $g$ with respect to the image $\mathrm{f}$. In practice, the algorithm applies this procedure to a series of subsets, which are portions of the reference image. Correlation code searches also for rotation and deformation of the subset in addition to its displacement. The repetition of this procedure makes it possible to obtain a mapping of the displacements between the two images. This map gives the mean value of the displacement of each subset. Thus having the smallest possible subsets involves a finer resolution for the field of displacements. However, if the selected subset is too small, the correlation operator has "insufficient information" to retrieve the next subset on the other image, as the number of potential "false friends" increases, and the sensitivity to digital noise of the sensors becomes critical. This approach is called local because each subset is analyzed independently of its neighbors, and allows measure movements of $<1 / 10$ th of a pixel.

For the SPT, a specific instrumented non-standard setup with a furnace has been designed, it allows mechanical testing in natural air in the temperature range $25^{\circ} \mathrm{C}-1000{ }^{\circ} \mathrm{C}$, and up to $10 \mathrm{kN}$ [16]. The sample deflection is measured by a laser micrometer acting as extensometer, through the measurement of the displacement of an alumina rod resting in the center of the specimen. The thermal control guaranties temperature homogeneity in the furnace of $0.5{ }^{\circ} \mathrm{C}$ between the top and the bottom parts of the device. The European "Code of Practice" CWA 15627:2006 [17] suggests a standard geometry of samples, smaller than that the one adopted here [12-14,18-20]. This guideline proposes to clamp rigidly the outer part of the disc between the receiving and the counter die, known as the down holder (Small Punch Bulge Test) or only to position loosely between them (Small Punch Drawing Test) to prevent from detrimental vertical deformation. In our case, a similar 


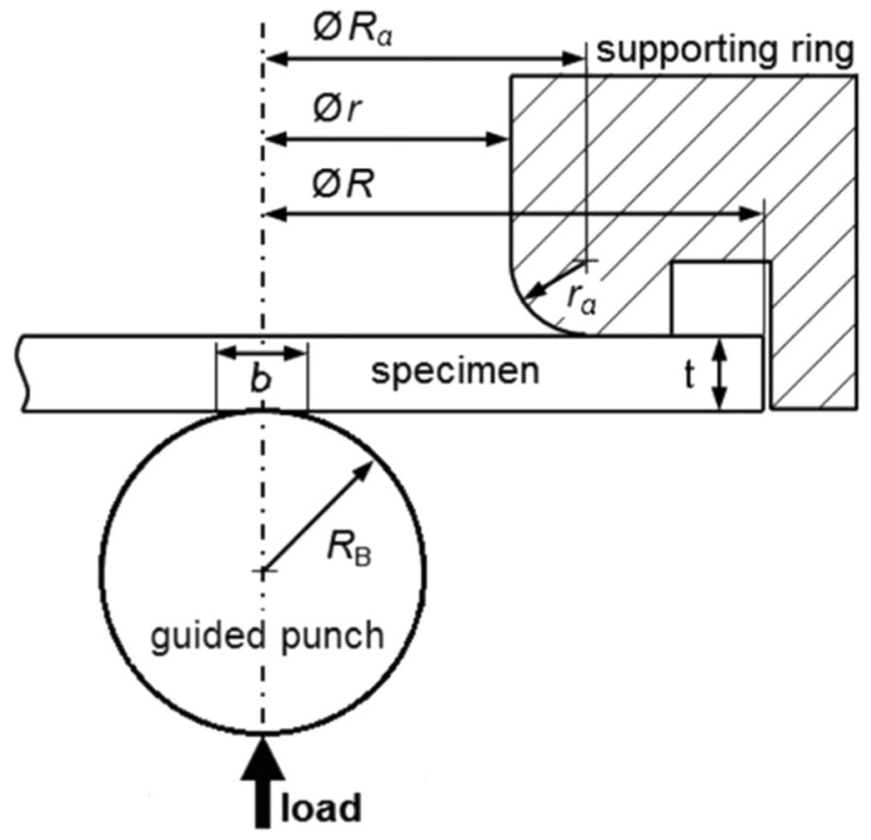

Fig. 1. Small punch test details.

SPT device without a down holder is used. This modified version of SPT should be called "Small Punch Bending Test" to refer correctly to the guideline [17] as was first proposed in [14]. This last point is critical for brittle fracture behavior with little or even no plastic deformation. The disc-shaped specimen (Radius $\mathrm{R}=10 \mathrm{~mm}$, total thickness around $2.1 \mathrm{~mm}$ ) is supported and centered by a ring (drawing radius $\mathrm{r}$ ) and loaded centrally by a spherical punch and then deformed up to failure (Fig. 1). The punch radius of $\mathrm{RB}=2.5 \mathrm{~mm}$ and the supporting ring radius of $\mathrm{Ra}=7 \mathrm{~mm}$ were chosen. The resulting stress field is axisymmetrical. The applied load, the punch displacement and the deflection are recorded during the test. The test is conducted in displacement-controlled mode with a constant punch velocity of $0.1 \mathrm{~mm} /$ min. Note that for tests at $850{ }^{\circ} \mathrm{C}$, a pre-charge of $25 \mathrm{~N}$ is applied using load control during the heating phase and temperature stabilization (total process duration is about $30 \mathrm{~min}$ ). For all the experiments, both 3 PB tests and SPT were repeated twice.

\section{Results}

\subsection{Points bending tests}

3PB tests were performed on TBC samples with two configurations: the punch is loading either the substrate side or the YSZ coating side leading respectively to a tension or a compression plane stress state within the ceramic coating. In order to simplify the references, the tension configuration (respectively the compression one) now corresponds to these two loadings. The tension or compression of the TBC system involves very different failure modes, driven by the ceramic failure.

Fig. 2 shows the curves of the load versus deflection at loading point for TBC specimens in both configurations. With the APS-TBC under tensile loading, progressive stages can be identified describing the implications of the experimental results: in the first part, the load - deflection curve is almost linear, and the specimen deforms elastically and accumulates elastic strain energy. Then the load reaches the critical value of around $150 \mathrm{~N}$. The load - deflection curve shows a localized maximum and minimum, similarly to a upper and lower yield during tensile testing of many alloys. Following this "yielding", the load increases further with the increase of the deflection with progressive loss of stiffness. The load reaches a plateau at around $350 \mathrm{~N}$ with a

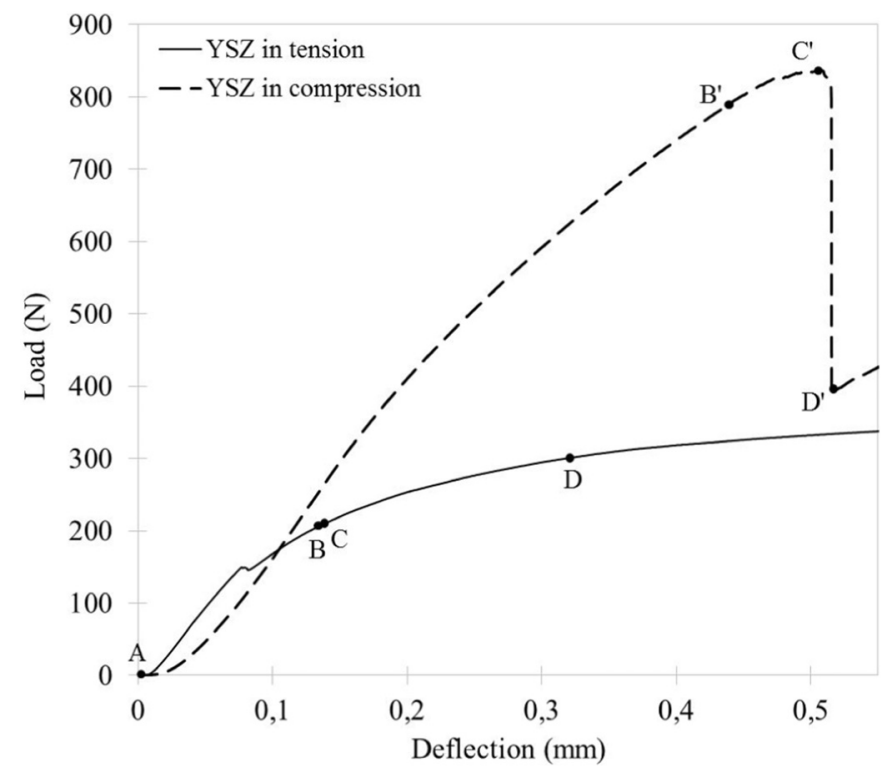

Fig. 2. Room temperature 3PB load - displacement curves of as-sprayed 3PB specimens with YSZ in tension a) before - b) after failure. The letters on the curve refer to images in Figs. 3 and 4.

continuous increasing deflection. The comparison with 3PB performed on substrate only specimens indicate that the end of the curve is mainly characteristic of the Hastelloy $\mathrm{X}$ behavior. The test was stopped at a final deflection of $0.8 \mathrm{~mm}$. The specimen revealed a clear plastic deformation of the metallic substrate while none part of the ceramic coating fell out.

For the other configuration, with the ceramic coating under compression, three stages can also be identified from the load - deflection curve. In the first part of the curve, an elastic deformation resulting in a linear trend is observed (the initial nonlinearity of the curve could be attributed to the mechanical clearance of the loading system). Then from about $350 \mathrm{~N}$, a nonlinear behavior characterized by a progressive decrease of the curve slope can be observed, before a sharp failure around $850 \mathrm{~N}$. At this point half of the ceramic coating fell out from the TBC, as the experiment was repeated several times, in some cases the YSZ coating fell entirely except just under the loading roll. The test was stopped at a final deflection of about $0.8 \mathrm{~mm}$.

\subsection{Failure modes and crack propagation paths}

The images recorded during 3PB testing demonstrate gave some insights on the failure mechanisms of TBC and rupture of the YSZ in both tension and compression configurations, thanks to the direct observation of cracks and moreover by displaying strain fields as deduced from DIC technic.

The four rows of the Fig. 3 shows four different stages of the 3PB test in tension, corresponding to the A,B,C,D points of the Fig. 2. The column to the left side, Fig. 3 a, d, g, j are raw optical images of the surface. On the center column, Fig. $3 \mathrm{~b}, \mathrm{e}, \mathrm{h}, \mathrm{k}$, the elongation field in $\mathrm{Y}$ vertical direction $(\varepsilon Y Y)$ of the sample estimated with DIC can be seen. Fig. $3 \mathrm{c}, \mathrm{f}, \mathrm{i}, 1$ represent the elongation field in $\mathrm{X}$ horizontal direction $(\varepsilon X X)$.The initial state, Fig. 3 a, b, c, before the beginning of the bending test reports the free deformation field, and highlights the main difficulty of the DIC method which is the loss of subsets tracking from one image to the next. Here, despite the surface texture of the specimens, the bright color of the YSZ with very few contrasts explains the tracking difficulties of the subsets in this region. However, the amount of correlated subsets during the bending test remains almost constant. At the yield in the slope of the curve, at $150 \mathrm{~N}$, the DIC analysis did not detect any event, cracking or elongation. This could be caused by the weak 

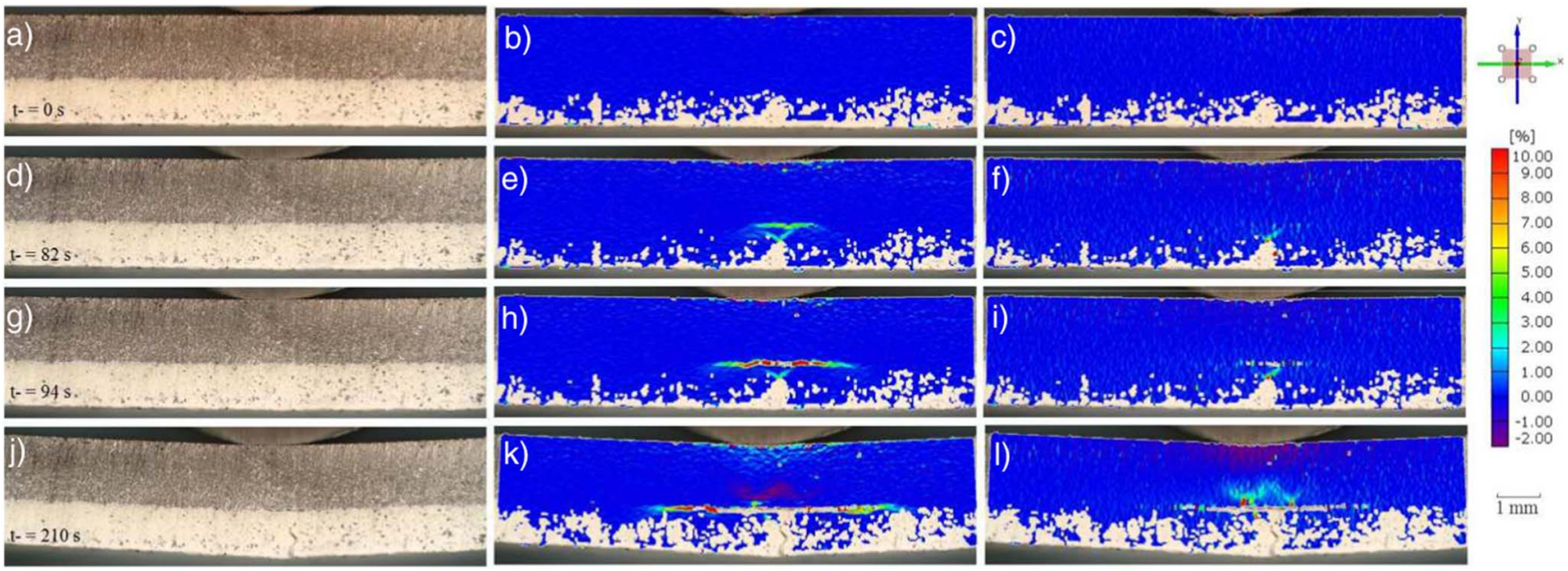

Fig. 3. Lateral view of the TBC during 3PB testing with YSZ in tension showing the raw images (a, d, g, j) and stain fields $\varepsilon Y Y$ (b, e, h, k) $\varepsilon$ XX (c, f, i, l). The successive rows correspond to the points A, B, C and D in Fig. 2.

resolution at the surface of the YSZ coating. One of the first images on which the crack appears, 30s later than the yield, corresponds to point $B$ of the Fig. 2 and is illustrated on Fig. 3 d, e, f. It is observed that a first segmentation crack initiates under the loading roll from the outer surface across the YSZ deposit, as can be hardly observed in Fig. 3d but is clearly revealed by strain field (or even by the loss of subset tracking). At the tip of this first crack in YSZ, the DIC reveals deformation lobes, oriented at $45^{\circ}$ away the crack on both sides of its tip. At the same time, an interfacial strain localization initiating delamination can be observed below the loading point, above the latter crack. It is very important at that point to notice that the segmentation crack and the lobes are not connected to the delamination crack.

At point C (12 s later), corresponding to the Fig. $3 \mathrm{~g}, \mathrm{~h}$, $\mathrm{i}$, the opening of the delamination crack along $\mathrm{Y}$ direction is clearly visible with high subsets deformation $(\varepsilon Y Y>10 \%)$ and subsets deletion when their deformation overcomes a critical threshold. On the contrary, the vertical (segmentation) crack does not spread clearly. The lobes and the delamination remain disconnected.

The final row corresponds to point $\mathrm{D}$ on the loading curve. Between points $C$ and D nearly 120 s elapse during which the delamination crack propagates in a stable manner. At that point, the vertical crack reaches the delamination with a strong opening of the previous elastic deformation right lobe, observable on Fig. $3 \mathrm{j}, \mathrm{k}, \mathrm{l}$. Another interesting information brought by the DIC analysis concerns the bond coat cracking for such strong deflection. Two cracks can be seen, on each side of the loading point, above which deformation lobes, both in $\mathrm{X}$ and $\mathrm{Y}$ directions, are also visible. The DIC analysis applied upon unloading, after testing (not shown here), exhibited remaining plastic deformation lobes localized in the substrate, confirming the plastic nature of the deformation lobes.

A similar analysis was performed for the test under compression stress of the ceramic coating. The images are showed in Fig. 4 with the same scheme that in the previous figure, column to the left is the raw image, middle column is the elongation strain field along $\mathrm{Y}$ direction $(\varepsilon \mathrm{YY})$ and column to the right represent the elongation field in $\mathrm{X}$ direction $(\varepsilon X X)$. The four deformation steps corresponding to the $\mathrm{A}^{\prime}, \mathrm{B}^{\prime}$, $C^{\prime}, D^{\prime}$ points of the Fig. 2 are arranged on the four row of Fig. 4. Fig. 4 a, $\mathrm{b}, \mathrm{c}$ set the reference position at $t=0 \mathrm{~s}$, free of any deformation. Then, almost no significant subsets deformation can be seen until almost $800 \mathrm{~N}$ after $286 \mathrm{~s}$ of testing (point B' of Fig. 2.). As shown on Fig. 4 d, e, $\mathrm{f}$, the first locally concentrated deformation along $\mathrm{Y}$ axis takes place at the interface between the bond coat and the top coat, on both sides of the punch, causing delamination. On X direction, only the tension deformation in the substrate is visible, confirmed with the negative deformation in Y direction in the same area, related to the Poisson strain.
Quickly, at $t=332 \mathrm{~s}$, Fig. $4 \mathrm{~g}$, h,i and point $\mathrm{C}^{\prime}$ of Fig. 2, the delamination crack propagates along the metal-ceramic interface of the sample in the direction of the ends. On the right side of the specimen, the crack spreads obliquely, in the direction of the loading point, through the coating. The local deformation can be observed despite the loss of subsets in this region, more in $\mathrm{Y}$ than in $\mathrm{X}$ direction. By the time this delamination reaches critical length, one half of the coating spalls abruptly. The released energy causes the complete delamination under the loading point of the specimen, as seen in Fig. 4 j, k, l.

\subsection{Small punch test}

\subsubsection{Room temperature tests}

The typical loading curves TBC systems under tensile and compressive loading tested in SPT at room temperature are showed in Fig. 5. In tension, similarly to the 3PB, the as-sprayed YSZ specimen exhibits a monotonous increase of the load in the first part of the load deflection curve. A decrease of the loading curve occurs around $500 \mathrm{~N}$, in a continuous manner, without the "yielding" phenomenon observed during tension 3PB. The load increases with the increase of the deflection with progressive decrease of slope. The load reaches a plateau at around $2700 \mathrm{~N}$.

When the ceramic coating is under compression, 3 stages can be identified from the load - deflection curve. In the first part of the curve, an elastic deformation resulting in a linear trend is observed, until $1600 \mathrm{~N}$ and $1800 \mathrm{~N}$. At that point a rapid decrease of load by $100 \mathrm{~N}$ is observed, similar to "yielding". After what, the load increases again, with a lower slope, and results in a sharp failure at $2100 \mathrm{~N}$ and $2250 \mathrm{~N}$ respectively, accompanied by a thumping sound during the test.

Figs. 6 and 7 show the disc-shape specimen of SPT after testing, in both configurations previously described (respectively YSZ in tension Fig. 6 - and in compression - Fig. 7). The first thing that can be observed is similarly to $3 \mathrm{~PB}$ tests, the failure mode is brittle. All the samples exhibit a failure joining at the center precisely at the load application point, by the punch, corresponding to the maximum stressed point. The other interesting point concerns resulting failure modes to biaxial mechanical solicitation. Indeed, they seem to correspond to a 3D extension of the 3PB test ones, for both configurations.

When the YSZ coating is under tension, cracks with a "star" shape can be seen at the surface on the opposite side of the loading point. At the end of the test, since in this configuration the top coat is upside, the pieces of broken ceramic remain in place as showed in Fig. 6.a. When taking the specimen out of the testing device, all these pieces fall away as showed in Fig. 6.b. An interrupted test before the breaking point was also performed (Fig. 6.c), revealing the earliness of the appearance of 

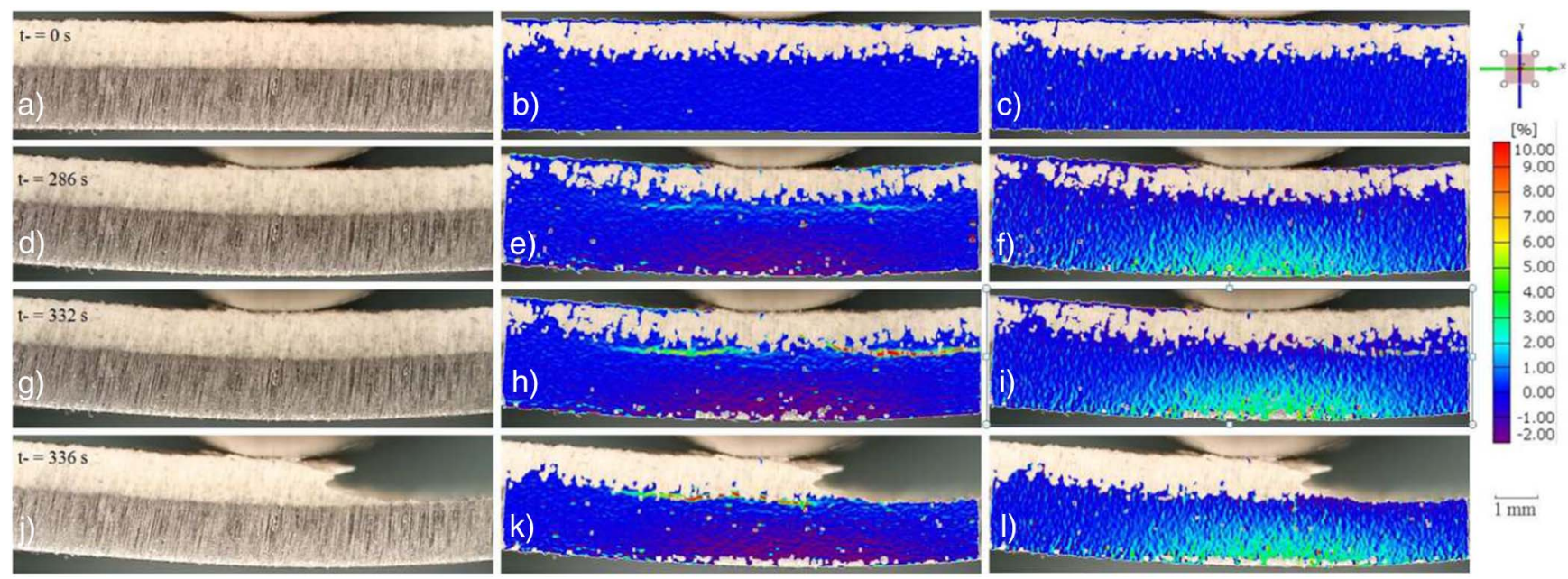

Fig. 4. Lateral view of the TBC during 3PB testing with YSZ in compression showing the raw images (a, d, g, j) and stain fields $\varepsilon$ YY (b, e, h, k) $\varepsilon X X$ (c, f, i, l). The successive rows correspond to the points $\mathrm{A}, \mathrm{B}^{\prime}, \mathrm{C}^{\prime}$ and $\mathrm{D}^{\prime}$ in Fig. 2.

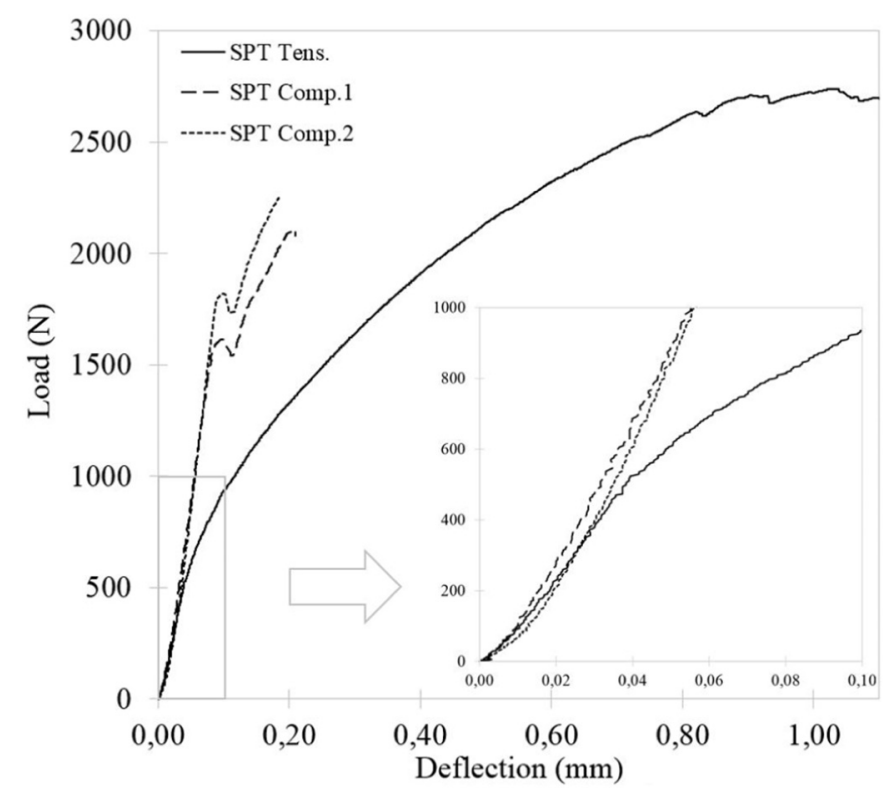

Fig. 5. Room temperature SPT load - displacement with YSZ under compression, and tension.

the first crack $(<500 \mathrm{~N})$, similarly to the 3PB test. On the failed specimen, delamination cracks are visible too.

For the compression configuration of the coating, the samples after failure reveal a total delamination of the YSZ coating, in quarters or thirds. This failure mode in quarter or third recalls the failure mode of free-standing YSZ specimens tested with the same SPT device [16] or more generally brittle materials submitted to SPT. Under the loading point, only a cone-shape of material remains, echoing the oblique deflection of delamination crack observed in 3PB.

\subsubsection{High temperature tests $\left(850^{\circ} \mathrm{C}\right)$}

At high temperature, only the compression configuration was tested. The associated load - displacement curve can be seen in Fig. 8. The noise that appeared on deflection measurement was caused by disturbances of the laser signal in the furnace, but does not prevent the main trends of the curve. The global shape looks like the room temperature curve, seen previously, except that in the present the "yield" phenomenon is no more observed. The loading curve is composed by a linear elastic part until $1800 \mathrm{~N}$, a similar value as compared to the room temperature test. The high temperature decreases however the stiffness as revealed by a less sharp slope. The following part corresponds to a lowering of the slope, but still linear, until $2200 \mathrm{~N}$, ending with a plateau. The load to failure is also similar at $850{ }^{\circ} \mathrm{C}$ than at room temperature. High temperature effects only lower the global stiffness of the specimen. No sintering effects are visible on the curves and the holding time is too low to activate any significant microstructural evolution.

The observation of the failure of samples solicited in compression exhibits a brittle fracture as well, but in this case, an indentation on the punch ball in the ceramic coating occurred during the testing. Fig. 9 illustrated samples after testing. Over two tested specimens, the first one exhibited exactly the same failure modes as at room temperature, except the presence of the indentation. The other one presented an indented coating with a visible delamination all around the edge, but the ceramic deposit was still attached to the substrate. The indentation reveals all the same a hardness decrease of the YSZ. By measuring the diameter of the impression, the indented depth was calculated to be around $350 \mu \mathrm{m}$.

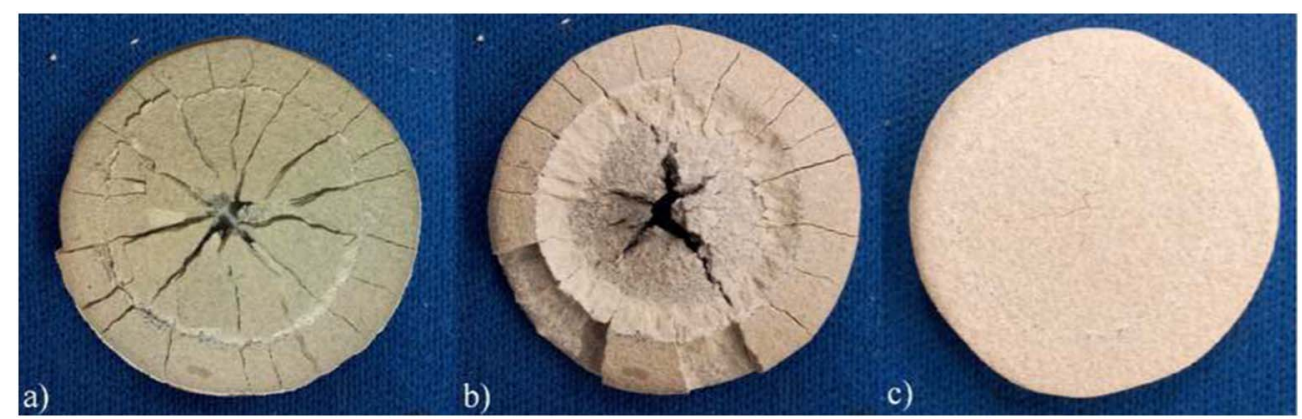

Fig. 6. Top view of as-sprayed SPT specimens after failure with YSZ in tension, tested at room temperature: tested sample with broken top coat still (a), without (b), interrupted sample with star shape crack (c). 


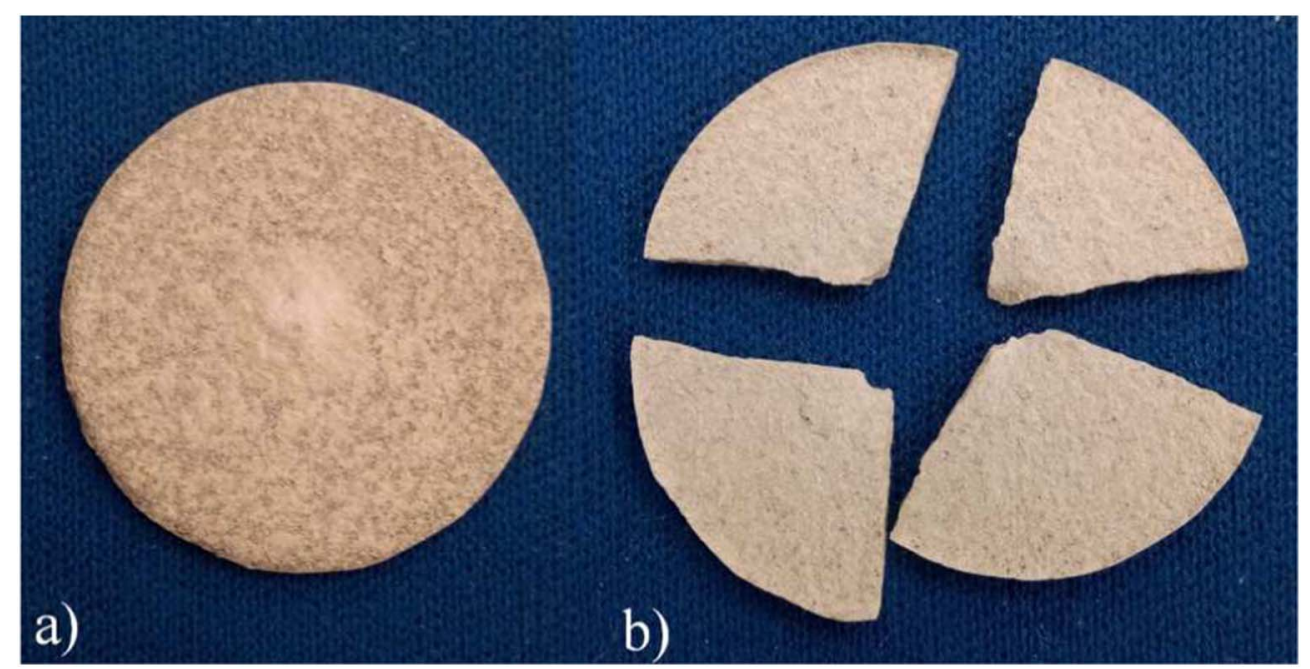

Fig. 7. Top view of as-sprayed SPT specimens after failure with YSZ in compression, tested at room temperature: spalled substrate (a), pieces of broken delaminated top coat (b).

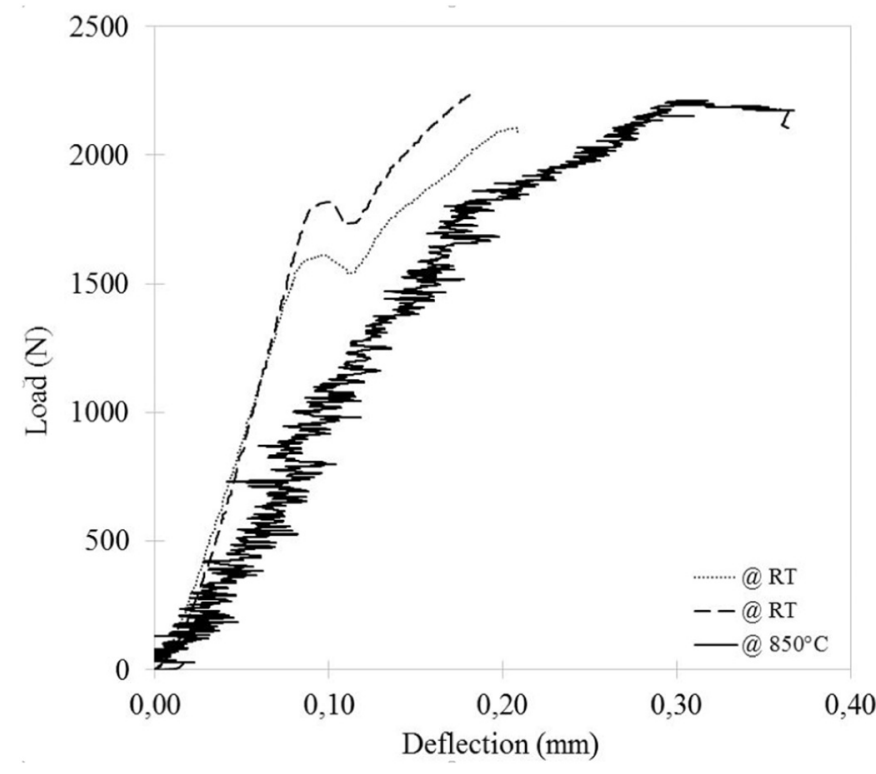

Fig. 8. Top view of as-sprayed SPT specimens after failure with YSZ in compression tested at $850{ }^{\circ} \mathrm{C}$ : spalled substrate (a), pieces of broken delaminated top coat (b).

\section{Discussion}

The crack propagation behavior of the ceramic thermal barrier coatings (TBCs) submitted to in plane uniaxial tensile stresses at room temperature, in as received unoxidized conditions had been revealed using the DIC technique associated with the 3PB test. The sensitivity of the ceramic coating to tensile stresses involves the early segmentation cracking of the ceramic coating, underneath the loading roll. This segmentation crack initiates at outer surface and propagates towards the center of the sample. However the crack is stopped with the YSZ top coat. At the tip of the crack, local deformation lobes are clearly visible. Yang et al. [23] applied DIC on SENB tests, but they did not observed such localized deformation zones. The segmentation crack grows linearly in the TBC with increase in bending load. Ray et al. [24] showed that the propagation occurs until about the yield point of the superalloy is reached. We observed that the crack stops before it reaches the interface between the ceramic layer and the bond coat on which at the same time a local deformation produces, leading to a delamination crack that expands steadily. For higher deflection values, small segmentation cracks are visible into the NiCrAlY bond coat and deflect at the interface with the substrate. The failure of TBC under tension exhibited no sudden or brutal spallation of the YSZ deposit, but a progressive delamination in a stable manner. Bialas et al. [25] revealed that crack propagation in the TBC is a relatively slow process when compared to the cracking of bond coat.

The results of bending obtained in this study can be compared the literature in terms of crack paths. Zhou et al. [26] show that due to

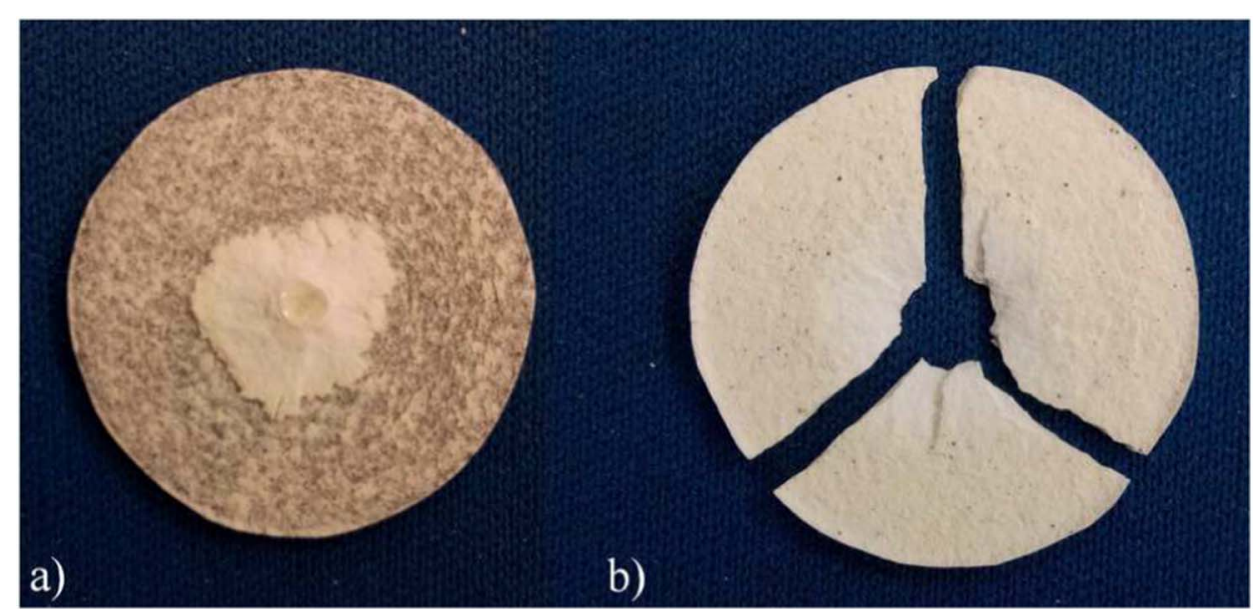

Fig. 9. Room temperature and high temperature $\left(850^{\circ} \mathrm{C}\right)$ SPT load - displacement with YSZ in compression. 
increased loading, the segmentation crack deflected at the $\mathrm{BC} / \mathrm{TBC}$ interface leading to delamination of the protective layer but we observed that segmentation and delamination cracks can be discontinuous. During four points bending tests with the APS-TBC under tensile loading. Andritschky et al. [27] observed that segmentation cracks formed usually with a constant spacing equal to the doubled value of TBC thickness. Bialas et al. [25] revealed that crack extension from the free surface of the TBC to the TBC/BC interface was correlated with the strain value of $0.8 \%$. Cracking of the bond coat appeared nearly instantaneously. The formation of bond coat cracks can be recognized also by small load dips of the bending curve. Ray et al. [24] highlighted that the crack path trajectory in the TBC (ceramic layer) often showed crack branching and crack deflection.

Under the compression configuration, the ceramic coating is submitted to compressive stresses but also to shear stresses generated at the metal-ceramic interface. During the increase of the loading, the interface undergoes localized deformation on both sides of the loading point, reaching subsequent important strain values causing delamination. Four point bending tests with the coating under compression made by Moriya et al. [28] revealed delamination cracks at the BC/TBC interface. Strain values after pre-oxidation were lower when compared to the non-oxidized specimens. On the same way as seen previously, a deflection in the crack path appears, but contrary to the tension configuration, the deflection goes from the interface into the coating, to the free surface. Then crack orientation becomes $45^{\circ}$, joining the surface of the ceramic at the loading point, resulting in the sharp failure of the specimen. This kind of loading has not been so much studied by authors is poorly documented in the literature, no comparative observation can be made about the crack deflection.

As discussed in the introduction of this paper, using SPT instead of 3PB presents several advantages when testing TBC systems. In particular, the biaxial stress loading that prevails in SPT is closer from the application loading conditions, and allows considering edge effects negligible. The results of SPT on TBC presented in this study confirm that damage initiates at the center of the disk specimen and that the contribution of edge effect to the failure is small. The comparison between 3PB and SPT results show that failure modes are quite similar with comparable fracture path for compression or tensile stress state in the top coat. However, changing from uniaxial (3PB) to biaxial (SPT) stress state significantly changes the loading curve, in terms of load and displacement level but also modifies the global shape of the curve. Currently, numerical simulations are done in an attempt to understand the different behaviors observed. In addition, the SPT apparatus has a cylindrical geometry which allows setting a heating system on it to be able to carry out test at temperatures close to the real operating temperature of the TBC system.

\section{Conclusion}

3PB tests and SPT have been carried out on APS TBC systems. DIC analysis of 3PB tests have highlighted the failure behavior of the YSZ coating under tension and compression loading.

In tension, segmentation crack of the top coating can early be observed, but the delamination initiate and spreads before the segmentation crack reaches the interface. The nucleation of delamination crack at the top coat/bond coat interface is not due to the deflection of SYZ segmentation cracks. The delamination crack expands smoothly with increased bending. For high values of bending deflection, segmentation cracks can be seen into the bond coat, provoking delamination at the substrate/bond coat interface.

In compression, delamination cracks are visible at the interface with the bond coat before the sudden spallation of the top coat in one or two pieces. Crack initiate at the bond coat/top coat interface, expands quickly on the interface and then deviate through the top coat, leading to its detachment.

A specific device has been developed for SPT of TBC systems. We could test disk specimens at room temperature and $850^{\circ} \mathrm{C}$. The comparison of SPT results with 3PB ones indicates that similar failure mechanisms may operate upon uniaxial or biaxial loading.

\section{References}

[1] Y. Kuroda, K. Fukaura, H. Sunada, H. Izumi, Mechanical properties of injection molded and sintered zirconia/alumina ceramic composites, J. Jpn. Soc. Powder Powder Metall. (Jpn.) 38 (6) (1999) 787-790.

[2] A. Feuerstein, J. Knapp, T. Taylor, A. Ashary, A. Bolcavage, N. Hitchman, Technical and economical aspects of current thermal barrier coating systems for gas turbine engines by thermal spray and EBPVD: a review, J. Therm. Spray Technol. 17 (2) (2008) 199-213.

[3] D. Schwingel, R. Taylor, T. Haubold, J. Wigren, C. Gualco, Mechanical and ther mophysical properties of thick PYSZ thermal barrier coatings: correlation with microstructure and spraying parameters, Surf. Coat. Technol. 108 (1998) 99-106.

[4] P. Planques, V. Vidal, P. Lours, V. Proton, F. Crabos, J. Huez, B. Viguier, Mechanical and thermo-physical properties of plasma sprayed thermal barrier coatings: a literature survey, Oxid. Met. (2017), http://dx.doi.org/10.1007/s11085-016-9693-1.

[5] H. Echosler, D. Renusch, M. Schütze, Proceedings of Turbomat Symposium, (2002), p. 17.

[6] H. Echosler, D. Renusch, M. Schütze, Conference Proceedings in Life Time Modeling of High Temperature Corrosion Process, (2001), p. 324

[7] H. Echosler, D. Renusch, M. Schütze, Mater. Sci. Eng. 20 (2004) 307.

[8] A. Kucuk, C.C. Berndt, U. Senturk, R.S. Lima, C.R.C. Lima, Influence of plasma spray parameters on mechanical properties of yttria stabilized zirconia coatings. I: four point bend test, Mater. Sci. Eng. A 284 (2000) 29-40.

[9] Y. Yamazaki, A. Schmidt, A. Scholz, The determination of the delamination resistance in thermal barrier coating system by four-point bending tests, Surf. Coat. Technol. 201 (2006) 744-754.

[10] Y. Zhao, A. Shinmi, X. Zhao, P.J. Withers, S. Van Boxel, N. Markocsan, P. Nylen, P. Xiao, Investigation of interfacial properties of atmospheric plasma sprayed thermal barrier coatings with four-point bending and computed tomography technique, Surf. Coat. Technol. 206 (2012) 4922-4929.

[11] P.F. Zhao, X.D. Li, F.L. Shang, C.J. Li, Interlamellar cracking of thermal barrier coatings with TGOs by non-standard four-point bending tests, Mater. Sci. Eng. A 528 (2011) 7641-7647.

[12] R. Morrell, N.J. McCormick, J. Bevan, M. Lodeiro, J. Margetson, Biaxial disc flexure-modulus and strength testing, Br. Ceram. Trans. 98 (1999) 234-240.

[13] A. Börger, P. Supancic, R. Danzer, The ball on three balls test for strength testing of brittle discs: stress distribution in the disc, J. Eur. Ceram. Soc. 22 (2002) $1425-1436$.

[14] S. Rasche, M. Kuna, Improved small punch testing and parameter identification of ductile to brittle materials, Int. J. Press. Vessel. Pip. 125 (2015) 23-34.

[15] S. Rasche, S. Strobl, M. Kuna, R. Bermejo, T. Lube, Determination of strength and fracture toughness of small ceramic discs using the small punch test and the ball on three balls test, Procedia Mater. Sci. 3 (2014) 961-966.

[16] P. Planques, V. Vidal, P. Lours, V. Proton, F. Crabos, J. Huez, B. Viguier, Mechanical Properties of Yttria-stabilized-zirconia for Thermal Barrier Coating Systems: Effects of Testing Procedure and Thermal Aging, (2017).

[17] CEN Workshop Agreement "Small Punch Test Method for Metallic Materials" CWA 15627:2007 D/E/F, 2007 December.

[18] Mao, H. Takahashi, Development of a further-miniaturized specimen of $3 \mathrm{~mm}$ diameter for tem disk ( $\$ 3 \mathrm{~mm}$ ) small punch tests, J. Nucl. Mater. 150 (1987) 42-52.

[19] K. Matocha, P. Cizek, L. Kander, The Evaluation of Actual Mechanical Properties of Materials by Small Punch Tests, Material \& Metallurgical Research, Ostrava, Czech Rep, 2006.

[20] T.E. García, C. Rodríguez, F.J. Belzunce, C. Suárez, Estimation of the mechanical properties of metallic materials by means of the small punch test, J. Alloys Compd. 582 (2014) 708-717.

[23] X.S. Yang, J. Wan, C.Y. Dai, Y. Zhang, W.G. Mao, Y.C. Zhou, C. Lu, Finite element analysis of crack propagation and fracture mechanical properties of free standing 8 wt. \% $\mathrm{Y}_{2} \mathrm{O}_{3}-\mathrm{ZrO}_{2}$ coatings, Surf. Coat. Technol. 223 (2013) 87-91.

[24] A.K. Ray, R.W. Steinbrech, Crack propagation studies of thermal barrier coatings under bending, J. Eur. Ceram. Soc. 19 (1999) 2097-2109.

[25] M. Białas, P. Majerus, R. Herzog, Z. Mroz, Numerical simulation of segmentation cracking in thermal barrier coatings by means of cohesive zone elements, Mater. Sci. Eng. A 412 (2005) 241-251.

[26] Y.C. Zhou, T. Tonomori, A. Yoshida, L. Liu, G. Bignall, T. Hashida, Fracture characteristics of thermal barrier coatings after tensile and bending tests, Surf. Coat. Technol. 157 (2002) 118-127.

[27] M. Andritschky, P. Alpuim, D. Stover, C. Funke, Study of the mechanics of the delamination of ceramic functional coatings, Mater. Sci. Eng. A271 (1999) 62-69.

[28] S. Moriya, Y. Kuroda, M. Sato, M. Tadano, A. Moro, M. Nino, Research on the application of PSZ/Ni FGM thermal barrier coating to the combustion chamber (damage conditions of TBC and its mechanism), Mater. Sci. Forum 308-311 (1999) 416-421. 